\title{
Seroepidemiological study of Helicobacter pylori infection in infancy
}

\author{
Merja Ashorn, Ari Miettinen, Tarja Ruuska, Pekka Laippala, Markku Mäki
}

Department of Paediatrics, University Hospital of Tampere and University of Tampere, Medical School

M Ashorn

T Ruuska

Department of Clinical Microbiology,

University Hospital of Tampere

A Miettinen

University of

Tampere, Department of Public Health

P Laippala

University of Tampere, Institute of Medical Technology

M Mäki

Correspondence to:

DrM Ashorn, Department of Paediatrics, University

Hospital of Tampere, 33101

Tampere, Finland.

Accepted 5 October 1995

\begin{abstract}
The incidence of Helicobacter pylori infection in very young children was determined, based on the emergence of specific IgG antibodies in sequential serum samples from birth to 2 years of age. The risk of acquiring $H$ pylori infection in infancy as a result of maternal exposure to the organism was also assessed, based on the determination of maternal cord-blood antibodies. Serum IgG class $H$ pylori antibodies were analysed in the cord blood samples of 195 newborns and in their follow up samples until the age of 2 years. Maternal antibodies were detected in the cord-blood samples of 21 children $(10 \cdot 6 \%)$. These antibodies disappeared in all but one child before 7 months of age and no new seroconversions occurred in these children. Ten originally cord-blood negative children seroconverted up to the age of 2 years $(5 \cdot 1 \%)$.

It is concluded that a major proportion of $H$ pylori infections observed in young adults in Finland are acquired during the first two years of life. Maternal seropositivity is not a straightforward risk factor for acquiring $H$ pylori infection in infancy. (Arch Dis Child 1996; 74: F141-F142)
\end{abstract}

Keywords: Helicobacter pylori, cord-blood antibodies, maternal seropositivity.

Helicobacter pylori infection occurs all over the world, and more than $50 \%$ of adults are infected

from a serum pool of 741 sera were selected for study. The samples had originally been collected from term infants born at Tampere University Hospital between October 1984 and July 1985 for a study on childhood diarrhoea. ${ }^{7} \mathrm{H}$ pylori antibodies were determined in the cord-blood samples and in follow up samples taken as follows: at the age of 28 days and at 7,12 , and 24 months after birth. An additional blood sample taken at the age of 18 months was available from 66 children. Only three follow up specimens were available from 18 children and only two from 19 . The sera had been stored at $-20^{\circ} \mathrm{C}$ until analysis.

IgG class $H$ pylori antibodies were determined by an enzyme immunoassay (EIA) using acid glycine extract antigen derived from $H$ pylori strain ATCC 43504 (NCTC 11637). ${ }^{8}$ The sequential serum samples from each child were analysed in parallel to minimise the interassay variation. Antibody titres were expressed as relative EIA units (EIU). The cutoff for seropositivity was determined as 20 EIU, based on the distribution of antibodies in culturally confirmed $H$ pylori positive and negative children. ${ }^{9}$

In the statistical analysis proportions with $95 \%$ confidence intervals (CI) were calculated for the annual incidence.

\section{Results}

Maternal antibodies to $H$ pylori were detected in the cord-blood samples of $21(10.6 \%)$ children. These antibodies disappeared in the later specimens of all but one child during the follow up until 7 months of age. Thus only one infant born seropositive remained so throughout the follow up period. No new seroconversions occurred in these 21 children.

During the first two years of life seroconversions from negative to positive were registered in $10(5 \cdot 1 \%)$ children, all of whom were cord-blood negative (fig 1). The median age for seroconversion was 18 months. Three seroconversions took place during the first year and seven during the second. The annual incidence of $H$ pylori infection was calculated to be $1.5 \%$ (95\% CI $0.32,4.43)$ during the first year of life and $3.7 \%(95 \%$ CI $1.48,7.37)$ during the second. The other $164(84 \cdot 1 \%)$ children remained seronegative. The total incidence of $H$ pylori infection in Finnish children from birth to 24 months of age was $5 \cdot 6 \%$. exposure to $H$ pylori, as reflected by cord-blood antibodies, increases the risk of acquiring $H$ pylori infection in infancy.

\section{Methods}

One hundred and ninety five consecutive sera

\section{Discussion}

The $H$ pylori antibody positivity registered in the cord-blood samples reflects the maternal antibody status of other similar infections. The 
Time course of the serum IgG antibody response to Helicobacter pylori in children from whom sequential samples had been obtained as newborns and up to 24 months of age. Results are only shown for those subjects who exceeded the cutoff for seropositivity during follow up.

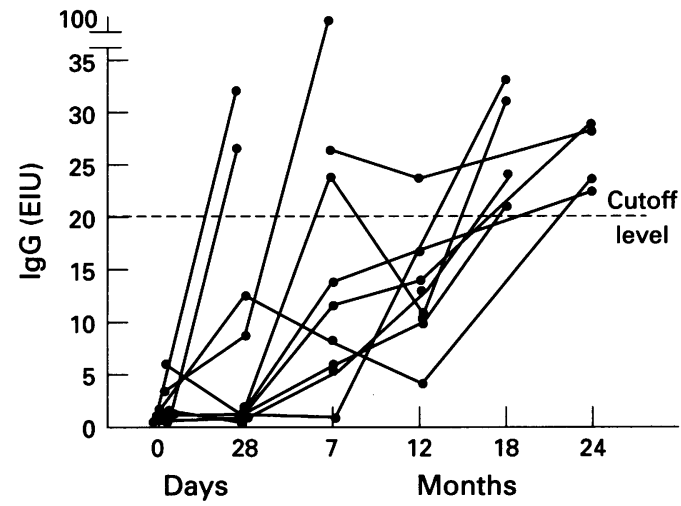

amount of seropositive mothers, $10 \cdot 6 \%$, agrees with a study of Finnish children and blood donors. ${ }^{89}$ Therefore, our study indicates that half of the $H$ pylori infections occurring in young adults in Finland are acquired during the first two years of life. We have already shown that seropositive children usually remain so until adolescence, indicating the long term course of the infection. ${ }^{9}$ The slight fluctuations in the antibody titres seen in some children can probably best be explained by the temporary effect of antibiotics so commonly used in this age group.

Based on current observations and on our earlier results showing that over $6 \%$ of 3 year old children had measurable $H$ pylori antibodies, ${ }^{9}$ it seems that the risk of infection is very low after reaching toddler age. Thus the incidence of $H$ pylori infection in children after the first years of life is likely to be similar to that of adults in developed countries. ${ }^{510}$

It could be speculated that the incidence figures obtained here might have been different if sera from children born in the 1990s had been studied. A recent cohort study on the prevalence of gastritis in Finland from 1918 to 1957 suggested that the rate of acquisition of $H$ pylori has declined quite rapidly during the past decades in this country. ${ }^{11}$ This change is most probably attributable to an improvement in socioeconomic conditions in Finland, as has been shown to be the case elsewhere. ${ }^{12}$ Over the past 10 years the conditions have, however, remained basically the same and therefore our material can be considered representative even for today.

In earlier studies seropositivity to $H$ pylor was more common in parents of $H$ pylor infected children than in parents of noninfected children. ${ }^{13} \mathrm{~A}$ strong association has been found between infection of the mothers and the $H$ pylori colonisation of their children. ${ }^{6}$ According to our results, however, maternal seropositivity to $H$ pylori was not a straightforward risk factor for acquiring $H$ pylori infection in infancy and early childhood. We have no additional data, other than the seropositivity and verification (the breath test) of bacterial colonisation of the mothers Moreover, the mothers were not retested, which means that the mothers could have become infected during the follow up period. In one recent study, however, where mothers with positive IgG titres against $H$ pylori were confirmed to be colonised using the breath test, none of the 35 infants studied became infected during follow up until the age of 1 year. ${ }^{14}$ Other earlier serological studies have also shown that seropositivity in the IgG class is a highly specific indicator of active $H$ pylori infection. ${ }^{15}$ Considering the low annual incidence of $H$ pylori infection in adults in western countries, ${ }^{10}$ it is unlikely that more than one of the mothers of the seroconverting infants would have harboured $H$ pylori during the follow up.

Our results lead us to conclude that instead of increasing the risk of $H$ pylori infection, maternal seropositivity seems, in fact, to protect the infants from early infection. In Gambian children this was confirmed, when IgA antibodies secreted via breast milk turned out to have protected the infants from $H$ pylori infection. ${ }^{16}$ This could also be the explanation for our results, especially because in Finland the duration of breast feeding is generally long (in this study $71 \%$ of the infants were breastfed for seven months or longer). ${ }^{7}$ We have been unable to determine the source of the infection among the infants studied. Neither is it possible to extend the results obtained here to other paediatric populations, where infected mothers may well have a different role in transmitting the bacteria to their children. In terms of prevention, risk groups have to be determined within each population separately.

1 Megraud F. Epidemiology of Helicobacter pylori infection. Gastroenterol Clin North Am 1993; 22: 73-87.

2 Sullivan PB, Thomas JE, Wight DGD, Neale G, Eastham EJ, Corrah T, et al. Helicobacter pylori in Gambian children with chronic diarrhoea and malnutrition. Arch Dis Child 1990; 65: 189-91.

3 The Eurogast study group. An international association between Helicobacter pylori infection and gastric cancer. Lancet 1993; 341: 1359-62.

4 Banatvala N, Mayo K, Megraud F, Jennings R, Deeks J, Feldman RA. The cohort effect and Helicobacter pylori. f Infect Dis 1993; 168: 219-21.

5 Cullen DJE, Collins BJ, Christiansen KJ, Epis J, Warren JR, Surveyor I, et al. When is Helicobacter pylori infection acquired? Gut 1993; 34: 1681-2.

6 Drumm B, Perez-Perez GI, Blaser MJ, Sherman PM. Intrafamilial clustering of Helicobacter pylori infection. N Engl f Med 1990; 322: 359-63.

7 Ruuska T. Childhood diarrhoea. Thesis. University of Tampere, Tampere, Finland,1991.

8 Kosunen TU, Höök J, Rautelin HI, Myllylä G. Age dependent increase of Campylobacter pylori antibodies in blood dent increase of Campylobacter pylori antibodies

9 Ashorn M, Mäki M, Hällström M, Uhari M, Åkerblom HK, Viikari J, et al. Helicobacter pylori infection in Finnish children and adolescents: A serologic cross-sectional and follow-up study. Scand $\mathcal{f}$ Gastroenterol 1995; 30: 876-9.

10 Kuipers EJ, Pena AS, van Kamp G, Uyterlinde AM, Pals G, Pels NFM, et al. Seroconversion for Helicobacter pylori. Lancet 1993; 342: 328-31.

11 Sipponen $P$, Helske T, Järvinen $P$, Hyvärinen $H$, Seppälä K, Siurala $\mathbf{M}$. Fall in the prevalence of chronic gastritis over 15 years: analysis of outpatient series in Finland from 1977, 1985, and 1992. Gut 1994; 35: 1167-71.

12 Mendall MA, Goggin PM, Molineaux N, Levy J, Toosy T, Strachan D, et al. Childhood living conditions and Helicobacter pylori seropositivity in adult life. Lancet 1992; 339: 896-7.

13 Best LM, Veldhuyzen van Zanten SJO, Sherman PM, Bezanson GS. Serological detection of Helicobacter pylori antibodies in children and their parents. $\mathcal{F}$ Clin Microbiol 1994; 32: 1193-6.

14 Blecker U, Lanciers S, Lebenthal E, Vandenplas Y. Helicobacter pylori infection in infants born from seropositive mothers. Am f Gastroenterol 1994; 89: 139-40.

15 Kosunen TU, Seppälä K, Sarna S, Sipponen P. Diagnostic value of decreasing $\mathrm{IgG}$, IgA and IgM antibody titres after eradication of Helicobacter pylori. Lancet 1992; 339: 893-95.

16 Thomas JE, Austin S, Dale A, McClean P, Harding M, Coward WA, et al. Protection by human milk IgA against Coward WA, et al. Protection by human milk IgA against 121 . 